\title{
¿TÉCNICOS O POLÍTICOS?: RADIOGRAFÍA DEL SISTEMA DE NOMBRAMIENTO DE DIRECTIVOS EN AGENCIAS REGULATORIAS INDEPENDIENTES
}

\author{
TECHNICIANS OR POLITICIANS? A RADIOGRAPHY OF THE SYSTEM \\ FOR APPOINTING THE HEADS OF INTENDEPEDENT REGULATORY \\ AGENCIES
}

\section{Diego G. Pardow L. ${ }^{1}$}

\begin{abstract}
RESUMEN: Este trabajo analiza la experiencia sobre nombramientos en agencias regulatorias independientes usando una base de datos sobre múltiples nombramientos directivos, en diversas agencias regulatorias. Según ella, los estándares de independencia formal son bastante bajos. Exhiben mejores resultados los procesos llevados a cabo por la Corte Suprema, el TDLC, el Banco Central o con la confirmación del Senado, por lo que parece razonable avanzar hacia cuerpos colegiados y mayor transparencia.
\end{abstract}

Palabras clave: Agencias independientes, Nombramientos, Independencia formal.

\begin{abstract}
This paper analyzes the Chilean experience regarding process of appointing heads of independent regulatory agencies (IRA) using a database that gathers information of several appointments in different regulatory agencies. The data shows that standards of formal independence are rather low. The processes of selection led by the Supreme Court, the Antitrust Court or Central Bank show better results, so seems reasonable to continue with the incorporation of multi-member panels and transparency.
\end{abstract}

Keywords: Independent regulatory agencies, Appointing systems, Formal independency.

\section{INTRODUCCIÓN}

¿Qué significa que una agencia regulatoria sea independiente? Desde una visión tradicional de la burocracia, la independencia permite garantizar cierta objetividad en el ejercicio del poder, evitar que el juicio del funcionario se contamine con sus intereses subjetivos $^{2}$. La literatura actual sobre diseños institucionales, sin embargo, entiende por

1 Doctor en Derecho por la Universidad de Berkeley, profesor asistente del Departamento de Derecho Económico, Facultad de Derecho, Universidad de Chile. Correo electrónico: dpardow@derecho.uchile.cl. La investigación detrás de este trabajo fue realizada en el marco de un proyecto del Fondo Nacional de Investigación Científica y Tecnológica de Chile $\left(\mathrm{N}^{\circ}\right.$ 1150181). Agradezco enormemente la colaboración de mis ayudantes Danae Fenner y Alejandra Corvalán, así como las observaciones de un árbitro anónimo y los comentarios recibidos durante la XXI Conferencia de la Asociación Latinoamericana e Ibérica de Derecho y Economía (ALACDE). Cualquier error es de mi exclusiva responsabilidad.

2 En términos de Weber (1964) por ejemplo, esta es precisamente la justificación de la carrera funcionaria: evitar que el funcionario responda políticamente de sus decisiones permite asegurar su independencia de juicio. Esta independencia de juicio, a su vez, es lo que permite aproximarse al problema público desde una perspectiva científica y producir el conocimiento. 
independencia algo mucho más concreto. En este contexto, la independencia se refiere a una serie de mecanismos formales que protegen a la agencia de la influencia del Poder Ejecutivo, especialmente en los siguientes tres ámbitos: nombramiento de autoridades, toma de decisiones regulatorias y administración presupuestaria ${ }^{3}$.

La independencia en los sistemas de nombramientos apunta a mitigar la influencia del Poder Ejecutivo por la vía de involucrar a los restantes poderes del Estado en la selección de los directivos de la agencia ${ }^{4}$. Un ejemplo típico en Chile es el mecanismo de confirmación ante el Senado para los consejeros del Banco Central, o la confección de ternas por parte de la Corte Suprema respecto de ciertos ministros del Tribunal de la Libre Competencia ("TDLC"). Por su parte, también se considera como una forma de independencia formal la capacidad de una agencia para adoptar decisiones regulatorias por su cuenta, esto es, sin el concurso del gobierno y de manera vinculante para todo el mundo, incluyendo los restantes órganos de la administración del Estado. Esto es lo que sucede con los dictámenes de la Contraloría General de la República (“CGR”), y en menor medida, con las guías de la Fiscalía Nacional Económica ("FNE”) 5 . Finalmente, la independencia presupuestaria busca evitar que el gobierno utilice la ley de presupuestos como un sistema de premios y castigos $^{6}$. En este sentido, la Superintendencia de Bancos e Instituciones Financieras ("SBIF”) es financiada por las propias empresas reguladas, mientras que el Panel de Expertos en materia eléctrica tiene un sistema similar.

Este trabajo analiza la experiencia en nuestro país con el primero de estos ámbitos de la independencia formal, utilizando una base de datos inédita que reúne información sobre cerca de 200 nombramientos directivos, realizados en más de 20 agencias regulatorias diferentes, durante el cuarto de siglo comprendido entre los años 1990 y 2016. En síntesis, los datos muestran que nuestros estándares de independencia formal en materia de nombramientos directivos son bastante bajos. En cerca de un 50\% de los nombramientos el Poder Ejecutivo tuvo un control absoluto, esto es, realizó internamente todo el proceso de selección y designación de los candidatos. En la mitad de nombramientos restantes, por su parte, el Sistema de Alta Dirección Pública ("ADP”) constituye el principal contrapeso del gobierno: este organismo confecciona ternas en más de un $20 \%$ los casos. Finalmente, solo un $17 \%$ de los nombramientos fueron sujetos a confirmación por parte del Senado.

\footnotetext{
3 En la literatura norteamericana, los mecanismos que permiten clasificar a una agencia como independiente son: (i) dirección a través de un consejo pluripersonal, (ii) nombramiento a través de sistemas con frenos y contrapesos, (iii) mandato para regular una industria en particular o bien problemas transversales específicos, (iv) restricciones para su remoción por parte del presidente (Miller, 1986). Dentro de la tradición europea, por su parte, las condiciones para clasificar a una agencia como independiente son similares, aunque existe una mayor preocupación sobre los aspectos presupuestarios. Para una propuesta de un índice comprensivo sobre independencia formal, ver GILARDI, 2002.

O’CONNELl (2008).

Ver CoRdero (2015) pp. 553-556, para un análisis de la independencia decisional de la CGR. Respecto de la FNE, la incorporación del sector público dentro de su ámbito de competencia tiene varios desafíos normativos, especialmente luego de la creación de un tribunal especializado para compras públicas. Ver, v.g. NEHME
} (2011).

6 Epstein y O’Halloran (1999). 
Desde otra perspectiva, la gran mayoría de nuestras agencias regulatorias siguen el modelo de las superintendencias, esto es, organismos legalmente descentralizados y cuya dirección está entregada a una autoridad unipersonal. En este tipo de agencias los directivos se mantienen por cerca de 3 años en sus cargos, lo que representa menos de la mitad del tiempo que duran en sus cargos los directivos del Banco Central, el TDLC y otros organismos con mayores niveles de independencia formal (6,3 años en promedio). Según se verá, la justificación de agrupar instituciones formalmente tan diferentes, como ocurre con los servicios descentralizados que pertenecen al Poder Ejecutivo, las denominadas autonomías constitucionales, e incluso organismos como el TDLC que pertenecen al Poder Judicial, obedece tanto a razones metodológicas como de Derecho Comparado. En cualquier caso, también se observa cierto patrón electoral en los nombramientos de directivos, concentrándose un volumen importante de ellos durante el primer año de cada período presidencial. Finalmente, el modelo de las superintendencias muestra un sesgo de selección hacia directivos con menor calidad profesional y una militancia política más intensa. Con todo, la manera de medir ambas circunstancias tiene varios supuestos discutibles y la tendencia de los datos en este punto es bastante menos clara que en otros países. Teniendo en cuenta lo anterior, la principal contribución de este trabajo es mostrar que parece razonable seguir avanzando hacia la incorporación de cuerpos directivos colegiados, así como de sistemas de nombramiento con frenos y contrapesos efectivos.

Antes de continuar la exposición, sin embargo, es importante recordar cuáles son las ventajas y desventajas asociadas con la independencia formal. La literatura distingue dos planos diferentes en el debate sobre agencias regulatorias independientes: el primero estaría marcado por la disyuntiva estabilidad-legitimidad, mientras que el segundo lo estaría por la disyuntiva tecnicismo-armonía. Respecto de la primera, una de las principales ventajas de la independencia consiste en otorgar estabilidad a las reglas que gobiernan una determinada actividad económica. Especialmente cuando existe polarización política respecto de una regulación en particular, la independencia actúa como un mecanismo de restricción recíproca, haciendo que los distintos actores en disputa converjan hacia una posición de consenso que se mantiene estable en el tiempo ${ }^{7}$. En materia de nombramientos, por ejemplo, el mecanismo de confirmación por parte del Senado típicamente genera que el candidato de la coalición política gobernante tenga que convencer a todo o parte de la coalición opositora. Ello, a su vez, generaría que los candidatos presentados a confirmación tengan una posición más moderada que la que tendría un candidato designado unilateralmente por la coalición gobernante ${ }^{8}$.

\footnotetext{
Este marco conceptual se construye a partir del denominado "principio del aliado", donde la cercanía ideológica entre el gobierno incumbente y los directivos de la agencia constituye el elemento decisivo para restringir o dar libertad a una agencia regulatoria. De este modo, los cambios de gobierno debieran llevar aparejado un cambio en la visión regulatoria de la agencia. La independencia surge, así como una manera establecer un compromiso intertemporal respecto del enfoque regulatorio de la agencia y moderar la magnitud del cambio político (Levy y Spiller, 1996).

También es posible que la moderación de la agencia, particularmente si se trata de una agencia bajo dirección de un cuerpo colegiado, tenga lugar mediante el desarrollo de un sistema de turnos. En este sistema, la coalición incumbente nombraría a uno de los miembros directivos según sus propias preferencias, pero luego la coalición opositora haría lo mismo con el siguiente cargo vacante. A nivel agregado, la dirección de la agencia
} 
En otras palabras, los mecanismos de independencia formal limitan la capacidad del Poder Ejecutivo para implementar las políticas de su preferencia. Tratándose del sistema de nombramientos, lo que se limita es la capacidad del gobierno para utilizar los nombramientos y remociones como un mecanismo para disciplinar el comportamiento de la agencia. Ahora bien, teniendo en cuenta que las autoridades de gobierno son elegidas democráticamente y los directivos de las agencias regulatorias no lo son, establecer límites a la libertad del Ejecutivo para decidir sobre los nombramientos acarrea siempre problemas de legitimidad. En el extremo, los nombramientos pueden ser usados estratégicamente por el gobierno incumbente, aprovechando una mayoría transitoria para hacer más difícil que futuros gobiernos introduzcan cambios regulatorios. Esto es lo que la literatura denomina una dinámica de atrincheramiento? .

De este modo, la decisión acerca de cuánta independencia resulta óptima exige ponderar los valores opuestos de estabilidad y legitimidad. Tratándose de consensos reales, el argumento a favor de la estabilidad se sostiene en que la pérdida de legitimidad sería pequeña, toda vez que la política implementada es similar al promedio que resultaría de la alternancia en el poder entre las distintas coaliciones en disputa ${ }^{10}$. Por el contrario, la pérdida de legitimidad es importante cuando existe una dinámica de atrincheramiento y la agencia resulta capturada por uno de los extremos del espectro político. Junto con existir un desacople inicial entre la voluntad mayoritaria y las políticas implementadas por la agencia, los mecanismos de independencia formal limitan la capacidad del ciclo electoral para corregir ese sesgo en el futuro ${ }^{11}$.

La segunda dicotomía apunta a la necesidad de establecer un balance entre otros dos valores opuestos, esta vez, tecnicismo y armonía. Muchas veces vemos a los mecanismos de independencia formal como herramientas para mejorar la calidad de las decisiones regulatorias ${ }^{12}$. En relación con los nombramientos, establecer un sistema de frenos y contrapesos implica que quien comienza con el proceso de selección debe convencer a otros organismos del Estado respecto de las virtudes de los candidatos que presenta. De manera similar a lo señalado anteriormente, ello genera incentivos para buscar personas cuya capacidad técnica se vea reflejada en la formación académica, experiencia profesional, y otros antecedentes objetivos. Por otra parte, limitar la remoción discrecional de los directivos de una agencia permite que las decisiones regulatorias sean adoptadas sin temor a represalias. En otras

\footnotetext{
contaría con un número similar de miembros provenientes de cada coalición. En Chile, este sistema de turnos en los nombramientos de cuerpos directivos colegiados pareciera haberse desarrollado durante el periodo de transición a la democracia (CAVALLO, 1998: pp. 125-138).

9 Un ejemplo recurrente es la Interstate Commission of Commerce, creada en EE.UU. hacia fines de 1887. La legislación que establecía esta agencia y nombraba a su cuerpo directivo fue aprobada por una mayoría del saliente Partido Demócrata, luego de haber perdido las elecciones y pocos meses antes de que la entrante mayoría del Partido Republicano asumiera sus funciones. Lejos de representar un consenso respecto de la posición de ambas coaliciones -los demócratas apoyaban la fijación de precios y los republicanos la libertad tarifaria-, la maniobra buscaba sencillamente limitar la capacidad del gobierno entrante para cambiar la regulación (WOOD Y BоОтне, 2004).

10 LEWIS (2004).

11 Tirole (1994).

12 BAWN (1995).
} 
palabras, los mecanismos de independencia formal buscan que los nombramientos estén motivados por la idoneidad técnica del candidato, antes que por su lealtad política ${ }^{13}$. Como se aprecia, estos mecanismos rompen con la verticalidad y jerarquía que caracteriza al Poder Ejecutivo. Aumentar la independencia institucional es una manera de generar visibilidad, esto es, facilitar que los responsables de la agencia reciban crédito por sus aciertos y se hagan responsables de sus errores. Teniendo en cuenta que ejercer apropiadamente la función regulatoria toma tiempo y esfuerzo, la independencia funciona como una manera de recompensar a los reguladores por hacer bien su trabajo ${ }^{14}$.

$\mathrm{Al}$ igual que con la dicotomía anterior, sin embargo, el tecnicismo acarrea costos que resulta importante tener en cuenta. Junto con fomentar la capacidad técnica del regulador, se hace más difícil verificar el cumplimiento de sus objetivos institucionales, ampliando así el espacio de discrecionalidad efectiva con que la agencia toma decisiones ${ }^{15}$. A medida que la especificidad técnica de la regulación aumenta, también aumentan las asimetrías de información entre la agencia regulatoria y los órganos de representación política. Por otra parte, fomentar la responsabilidad individual de una agencia, lógicamente disminuye sus incentivos para colaborar con otros potenciales organismos involucrados. Cuando son los directivos quienes reciben directamente los castigos y recompensas, el proceso de toma de decisiones regulatorias pasa a estar gobernado por el interés particular de la agencia y no por el bienestar social ${ }^{16}$. Todo lo anterior afecta la armonía del sistema regulatorio, especialmente en aquellos ámbitos donde se superponen las competencias de distintas agencias ${ }^{17}$.

En definitiva, establecer cuántos mecanismos de independencia formal debieran incorporarse a la hora de nombrar a los directivos de una agencia, exige preguntarse qué tipo de regulación queremos fomentar. La respuesta a esta pregunta está lejos de ser obvia, ya que más independencia no siempre será sinónimo de una mejor regulación. Limitar la influencia del Poder Ejecutivo en los mecanismos de nombramiento supone fomentar liderazgos estables y técnicos dentro de una agencia, pero ello viene a expensas de erosionar la legitimidad de nuestras reglas y aumentar los costos que supone para el gobierno coordinar los espacios regulatorios compartidos ${ }^{18}$. Por tanto, la pregunta sobre el nivel de indepen-

\footnotetext{
13 Es útil aproximarse a este tópico desde la perspectiva de un problema de agencia. La ausencia de frenos y contrapesos en la designación permite que quien comienza el proceso busque satisfacer únicamente sus intereses, lo que se conoce como selección adversa. Por su parte, los límites en la remoción buscarían hacerse cargo del riesgo moral que supone delegar autoridad en una agencia regulatoria (KIEWIET y McCubBIns, 1991: pp. 22-38). En el caso de organismos públicos, el dilema entre idoneidad técnica y lealtad política suele caracterizarse como una decisión entre "profesionalizar" y "burocratizar" una agencia (WILSON, 1989: pp. 149-153).

14 STEPHENSON (2007).

15 Gailmard (2002).

16 Rose-AcKerman (1986).

17 Esto es lo que la literatura denomina "regulatory commons". BuZBEE (2003) refiriéndose a sectores de la regulación que por carecer de un "dueño" o responsable directo, siguen una lógica similar a los bienes comunes. En estos casos, la regulación queda sujeta a dinámicas de acción colectiva o pasividad recíproca, donde cada una de las agencias involucradas espera que sea alguna otra la que finalmente se haga cargo del problema.

18 Freeman y Rossi (2012).
} 
dencia óptima es una pregunta fundamentalmente empírica, que supone evaluar críticamente nuestra experiencia previa ${ }^{19}$.

Los apartados siguientes de este trabajo se abocan a dicha tarea. Para ello, la segunda sección revisa las características formales de las agencias involucradas. La tercera sección analiza los diferentes mecanismos de nombramiento observados en nuestra práctica administrativa y su dimensión temporal, destacando el ciclo electoral que pareciera haberse seguido en los últimos 25 años. La cuarta sección propone una metodología para evaluar la intensidad de la afiliación política y la calidad profesional de los directivos, comparando los resultados en ambas dimensiones respecto de cada agencia. La sección final consigna las conclusiones.

\section{2. ¿QUÉ ES UNA AGENCIA REGULATORIA INDEPENDIENTE?}

Un aspecto crucial a la hora de evaluar la experiencia chilena en materia de nombramientos directivos consiste definir apropiadamente el objeto de estudio. Para ello, resulta necesario adaptar el concepto de agencia regulatoria independiente a la realidad de nuestro Derecho Administrativo, justificando qué tipo de organismos públicos pueden ser considerados dentro de esta categoría. Siguiendo a algunos autores ${ }^{20}$, el candidato natural a ocupar esta posición en Chile son las superintendencias. En términos generales, el concepto de regulación económica surge en Derecho Comparado durante los procesos de privatización y reforma de la burocracia estatal, señalizando el tránsito desde un Estado que se encarga de proveer servicios públicos de manera directa hacia uno que regula el mercado creado por el retroceso del aparato público ${ }^{21}$.

En Chile, el origen histórico de algunas superintendencias se remonta a la misión Kemmerer de principios del siglo XX. Con todo, la utilización de este tipo de organismo público efectivamente se generaliza durante las privatizaciones de la década de los $80^{22}$. Su función principal era servir como un vehículo administrativo donde se localizarían las nuevas facultades de supervisión que asumía el Estado. De hecho, la literatura destaca que la decisión de crear nuevas superintendencias buscaba precisamente aumentar la separación formal con los organismos de gobierno, siendo la discrecionalidad en materia de nombramientos la principal diferencia con el estándar comparado en EE.UU. y Europa ${ }^{23}$. Desde

\footnotetext{
19 Krause y Meier (2003).

20 Cordero y García (2012).

21 La idea de agencias regulatorias tiene, desde esta perspectiva, un vínculo natural con los organismos públicos creados durante los gobiernos de Thatcher en el Reino Unido y de Reagan en EE.UU., en lo que suele conocerse como "new public management" (Moran, 2003)). El equivalente funcional para este proceso en Chile sería la denominada "revolución silenciosa" de los Chicago boys durante el régimen de Pinochet (HunNEus, 2000). Con posterioridad, sin embargo, la noción de agencia regulatoria se ha ido extendiendo para denominar aquellos organismos que fiscalizan agentes económicos o tienen una influencia directa en el funcionamiento de los mercados. Ello, con independencia de que hubiesen sido creado mucho antes de la década de los ochenta, como sucede con los bancos centrales y las autoridades tributarias, o bastante tiempo después, como sería el caso de las oficinas de protección al consumidor financiero.

22 García (2009).

23 García y Verdugo (2010).
} 
esta perspectiva, el concepto de agencia regulatoria independiente quedaría comprendido, en primer lugar, por la decena de superintendencias que se encuentran funcionando actualmente ${ }^{24}$.

Enseguida, si analizamos comparativamente el modelo de superintendencias, en Chile existen un número importante de organismos con un diseño institucional similar y que también actúan en el ámbito de la regulación económica ${ }^{25}$. En términos formales, las superintendencias se caracterizan por ser órganos legalmente descentralizados y cuya dirección es ejercida por una autoridad unipersonal ${ }^{26}$. Ambas características son compartidas por la FNE, el Servicio Nacional del Consumidor (“SERNAC”), el Servicio Nacional de Aduanas (“SNA”), el Servicio de Impuestos Internos (“SII”) y la Comisión Nacional de Energía (“CNE”). Por ello, resulta lógico considerarlos dentro de nuestra categoría de agencias regulatorias independientes. Ahora bien, además de su denominación como servicio o comisión, estos órganos descentralizados tienen una diferencia importante en términos de sus ámbitos de competencia material. La competencia de las superintendencias sigue una lógica institucional o por silos, estableciendo un regulador diferenciado para cada tipo de industria. Al contrario, las comisiones y servicios descentralizados siguen una lógica funcional, donde se les distribuyen competencias para proteger un interés de manera transversal. Así, por ejemplo, mientras la superintendencia competente para fiscalizar el patrimonio de una entidad financiera depende de si dicha entidad está constituida como un banco comercial, una compañía de seguros o una administradora de fondos de pensiones, la FNE tiene atribuciones para perseguir una eventual colusión de precios en cualquiera de estos mercados.

Agreguemos ahora una nueva capa de complejidad a nuestra comparación entre competencias materiales y diseño institucional. La descentralización supone establecer las atribuciones de la agencia a nivel legal, entregándole su propio patrimonio y personalidad jurídica. Con ello se suprime la relación de jerarquía que tradicionalmente existe entre una agencia encargada de regular un tema específico y el ministerio que desarrolla la correspondiente política sectorial, reemplazándola por lo que se conoce en la literatura como una relación de supervigilancia o tutela ${ }^{27}$. Como se aprecia, la generalidad de los servicios básicos, los mercados financieros, la libre competencia y otras áreas tradicionales de nuestra regu-

24 Además de la SBIF, mencionada anteriormente, el listado de superintendencias incluye las superintendencias de Casinos de Juego (“SCASINOS”), de Electricidad y Combustibles (“SEC”), de Educación (“SEDUC”), de Insolvencia y Reemprendimiento ("SIR", que sucedió a la de Quiebras), de Servicios Sanitarios (“SISS”), de Medio Ambiente ("SMA”), de Pensiones (“SPENSIONES”, que sucedió a la de Administradoras de Fondos de Pensiones), de Salud (“SSALUD”, que sucedió a la de Instituciones de Salud Previsional), y la de Valores y Seguros (hoy Comisión de Mercados Financieros "CMF").

25 La regulación económica suele dividirse en tres segmentos. El primero se refiere a la regulación de los mercados financieros. El segundo consiste en la regulación de servicios básicos como el agua potable, la electricidad o las telecomunicaciones, así como otro tipo de infraestructura pública con características de monopolio (v.g. puertos, aeropuertos, carreteras). El último incluye la regulación de un conjunto heterogéneo de intereses con una influencia directa en el funcionamiento de la economía, tales como la libre competencia, la protección del consumidor o del medio ambiente (NeWBerry, 2000: pp. 18-24).

26 Carmona (2002).

27 Los servicios públicos legalmente descentralizados dependen directamente del Presidente de la República, quedando sujetos a la supervigilancia de uno o más ministerios. Esta relación de supervigilancia, por su parte, suele ser definida en términos relativos, como aquella que permite una mayor autonomía frente a la subordina- 
lación económica están sometidas a la supervisión de uno o más servicios públicos descentralizados. No obstante, la industria de las telecomunicaciones presenta una situación particular. La Subsecretaría de Telecomunicaciones (“SUBTEL”) está dentro de la estructura jerárquica del Ministerio de Transportes, pero tiene atribuciones tarifarias y de supervisión similares a la CNE, la SEC o la SISS. Por esta razón fue igualmente considerada dentro del objeto de estudio de este trabajo.

Un segundo grupo de organismos que pueden considerarse como agencias regulatorias independientes es aquel formado por el Banco Central y la Contraloría General de la República ("CGR") ${ }^{28}$. Ambas forman parte de lo que nuestro Derecho Administrativo denomina autonomías constitucionales y tienen su origen en las políticas de estabilidad macroeconómica incluidas en las recomendaciones de la misión Kemmerer ${ }^{29}$. A diferencia del modelo de superintendencias, sin embargo, sus niveles de independencia formal fueron aumentando progresivamente en las décadas previas a las reformas que acompañaron el proceso de privatizaciones ${ }^{30}$. En comparación con otros países, los bancos centrales suelen formar parte de esta categoría de agencias regulatorias independientes. Más aún, los propios estándares de independencia formal suelen construirse por comparación con el diseño institucional de la autoridad monetaria ${ }^{31}$. Tratándose de la CGR, su incorporación no solamente se justifica por razones históricas, sino por la importante función que cumple en materia de tarifas de servicios básicos. Atendido que los decretos tarifarios están sujetos al trámite de toma de razón, buena parte de las discusiones entre la autoridad y la empresa regulada tiene lugar en esta sede.

Finalmente, existe un tercer grupo de organismos cuya naturaleza jurídica es particular, pero también resulta razonable incorporarlos dentro de la categoría de agencias regulatorias independientes. Se trata del Consejo para la Transparencia ("CPLT"), el Panel de Expertos en Materia Eléctrica y el TDLC. Todos ellos son órganos que intervienen en ámbitos tradicionales de la regulación económica, son dirigidos por un cuerpo colegiado y su diseño institucional busca establecer mecanismos de independencia formal respecto del Poder Ejecutivo. Estos tres organismos fueron creados durante los últimos 20 años, en un proceso de reformas institucionales gatillado por la admisión de Chile a la Organización para la Cooperación y Desarrollo Económico (“OCDE”). Al menos en parte, el diseño institucional de estos tres organismos responde a las exigencias explícitas de la OCDE en cuanto a mejorar el modelo de las superintendencias y fortalecer los estándares de independencia de nuestras agencias regu-

ción jerárquica tradicional. Ello se manifestaría, por ejemplo, en la ausencia de un recurso jerárquico respecto de las decisiones del jefe de servicio. Ver, Cordero (2015).

28 Vergara (2018).

29 Drake (1989) En ambos casos su diseño institucional buscaba limitar la influencia del Poder Ejecutivo, fomentando un compromiso de largo plazo respecto del volumen de gasto público. Mientras el propósito inicial de la CGR era controlar la ejecución presupuestaria y obligar a que el gobierno no gaste más de lo que tiene, el del Banco Central era contener los incentivos para financiar la expansión del gasto público mediante la emisión de moneda.

30 ZÚNiga (2007).

31 Gilardi (2002). 
latorias ${ }^{32}$. Con todo, aunque la incorporación del CPLT dentro de este grupo resulta pacífica en doctrina, las últimas dos instituciones exigen una fundamentación adicional ${ }^{33}$.

Mientras el Panel de Expertos suele considerarse como una institución jurisdiccional, el TDLC directamente forma parte del Poder Judicial ${ }^{34}$. Sobre la base de lo anterior sería posible argumentar que, al extender la categoría de agencias regulatorias independientes a estos dos organismos jurisdiccionales, sería razonable incorporar también a otros tribunales especializados. Así, por ejemplo, algunos autores tratan al TDLC y a los Tribunales Ambientales de manera análoga ${ }^{35}$. Pero evaluemos este argumento separadamente. La razón para incluir al Panel de Expertos y al TDLC es doble. Por una parte, los dos organismos tienen ciertas potestades normativas para establecer reglas de aplicación general, esto es, más allá de la resolución del caso concreto. De esta manera, su capacidad para desarrollar la regulación económica en materia de electricidad y competencia, exige considerar ambas instituciones dentro de nuestro objeto de estudio ya que materialmente realizan funciones que en Derecho Comparado son realizadas por agencias regulatorias independientes. Por otra, el nombramiento de buena parte de los ministros del TDLC corresponde al Banco Central, mientras que el nombramiento de los ministros del Panel de Expertos corresponde al TDLC. Desde una perspectiva metodológica, evaluar los resultados de los nombramientos en estas tres instituciones permite analizar este efecto delegado, donde una agencia independiente tiene a su vez atribuciones para incidir en el nombramiento de otra agencia diferente. Finalmente, la razón para excluir a los Tribunales Ambientales del estudio es únicamente práctica, toda vez que gran parte de los nombramientos de sus ministros fueron realizados una vez que el trabajo de campo se había realizado.

Una sistematización de las características formales de estos tres grupos de organismos se incluye en la Tabla 1. En la tabla aparecen los organismos en actual funcionamiento, sin perjuicio de que muchos de ellos han cambiado su estructura orgánica en los últimos 30 años, mientras que otros han sido fusionados o reemplazados. En síntesis, nuestro equivalente funcional al concepto de agencias regulatorias independientes estaría constituido por una veintena de organismos descentralizados que se encuentran funcionado bajo la denominación general de superintendencia, comisión o servicio. A ellas se agregan la FNE, que es un órgano descentralizado pero que actúa con otra denominación, y la SUBTEL, que es un órgano centralizado, pero con funciones análogas a las de una superintendencia. También se suman la CGR y el Banco Central como instituciones constitucionalmente autónomas. Finalmente, habría que incluir la situación particular del CPLT, el Panel de Expertos, el TDLC y otros organismos análogos. En el caso de estas instituciones con atribuciones jurisdiccionales, extender la noción de agencia regulatoria ciertamente erosiona las categorías tradicionales de nuestro Derecho Administrativo. Ahora bien, presenta ciertas ventajas metodológicas importantes, toda vez que permite comparar una muestra de instituciones mucho más heterogénea y comparable con la práctica regulatoria de otros países.

\footnotetext{
32 V. g. Morandé y díaz (2010).

33 RajeVIC (2010).

34 VERgara (2005).

35 Tapia y Cordero (2015).
} 
Tabla 1

Características generales de las agencias regulatorias ${ }^{36}$

\begin{tabular}{llclllll}
\hline \multicolumn{1}{c}{ Organismo } & \multicolumn{1}{c}{ Tipo } & Creación & Planta & Dirección & Sueldo & No. & Años \\
\hline Banco Central & Autónoma & 1925 & 635 & Plural (5) & 10 & 19 & 6.5 \\
CGR & Autónoma & 1927 & 1,600 & Unipersonal & 7.4 & 5 & 7.2 \\
SUBTEL & Centralizada & 1977 & 184 & Unipersonal & 7.8 & 7 & 2.3 \\
CNE & Descent. & 1978 & 51 & Unipersonal & 6.0 & 8 & 3.1 \\
FNE & Descent. & 1965 & 87 & Unipersonal & 7 & 4 & 4.0 \\
SBIF & Descent. & 1925 & 203 & Unipersonal & 8.4 & 7 & 3.8 \\
SCASINOS & Descent. & 2005 & 59 & Unipersonal & 8.3 & 3 & 3.9 \\
SEC & Descent. & 1985 & 199 & Unipersonal & 8.1 & 9 & 2.0 \\
SEDUC & Descent. & 2012 & 636 & Unipersonal & 7.6 & 2 & 1.5 \\
SERNAC & Descent. & 1990 & 160 & Unipersonal & 5.7 & 7 & 3.7 \\
SII & Descent. & 1902 & 4,295 & Unipersonal & 9 & 7 & 3.8 \\
SIR & Descent. & 2002 & 159 & Unipersonal & 8.3 & 5 & 6.1 \\
SISS & Descent. & 1990 & 148 & Unipersonal & 7.6 & 6 & 4.5 \\
SMA & Descent. & 2010 & 152 & Unipersonal & 8.9 & 3 & 1.3 \\
SNA & Descent. & 1979 & 1,464 & Unipersonal & 4.4 & 9 & 2.7 \\
SPENSIONES & Descent. & 1980 & 169 & Unipersonal & 8.4 & 7 & 3.5 \\
SSALUD & Descent. & 1990 & 262 & Unipersonal & 8.5 & 9 & 3.9 \\
CMF & Descent. & 1980 & 252 & Plural (5) & 8.3 & 8 & 3.1 \\
CPLT & Otro & 2009 & 132 & Plural (4) & 2.3 & 7 & 3.1 \\
Panel & Otro & 2004 & - & Plural (7) & 14.4 & 11 & 9.8 \\
TDLC & Otro & 2003 & 23 & Plural (5) & 8.4 & 11 & 4.9 \\
\hline Promedio & - & 1902 & 517,6 & - & 7,85 & 7,05 & 4,03 \\
\hline & & & & & & & \\
\hline
\end{tabular}

En términos generales, el tamaño de las distintas agencias varía considerablemente. En un extremo existen instituciones como el TDLC o el Panel de Expertos, que funcionan en una sola sede y tienen una planta de menos de 50 funcionarios. En contraste, organismos como la CGR o el SII tienen presencia territorial a lo largo de todo Chile y una

\footnotetext{
36 El año corresponde a aquel donde se crea la primera organización que precede a la actual. El sueldo corresponde a la remuneración nominal promedio recibida por los directivos de la agencia en el período correspondiente, mientras que la duración corresponde al promedio de años que los directivos se mantuvieron en sus cargos. La información incluida en esta tabla fue recogida de las respectivas leyes de presupuestos, memorias institucionales y otras fuentes de información públicas. El detalle con las fichas de investigación para cada institución puede consultarse en: https://www.researchgate.net/project/Dieseno-institucional-de-la-agenciasregulatorias-independientes-ARI-en-Chile
} 
planta que supera el millar de funcionarios ${ }^{37}$. En cuanto a la dirección, cerca de un 25\% de las agencias cuenta actualmente con un gobierno colegiado, mientras el $75 \%$ restante mantiene un liderazgo unipersonal. La tendencia en materia de diseño institucional, sin embargo, se mueve claramente hacia estructuras de gobierno colegiado. Con excepción de las superintendencias creadas en materia de educación escolar, medio ambiente y casinos de juegos, las reformas institucionales de los últimos 15 años privilegian la colegialidad ${ }^{38}$. Lógicamente, las instituciones que cuentan con gobiernos colegiados realizan un mayor número de nombramientos. Ahora bien, es importante destacar que la duración en el cargo de los directivos es también diferente. Los directivos duran cerca de 6 años en su cargo cuando se trata de instituciones con gobierno colegiado. Este promedio se reduce a la mitad para instituciones con gobierno unipersonal, donde los directivos duran cerca de 3 años.

En definitiva, una típica agencia regulatoria en Chile tiene un alto grado de especialización, encontrándose restringido su ámbito jurisdiccional a un mercado, industria o interés bien definido. Su diseño institucional responde al de un servicio público funcionalmente descentralizado, con un tamaño relativamente pequeño, una sola oficina a nivel nacional y cerca de una centena de funcionarios. La dirección del organismo, por su parte, tiende a recaer en un solo individuo cuya remuneración es cercana a los 8 millones de pesos y dura cerca de 4 años en su cargo.

\section{VEINTICINCO AÑOS DE NOMBRAMIENTOS}

Una vez definida esta idea aproximativa para las agencias regulatorias independientes, corresponde ahora continuar detallando el objeto de estudio. Además de los 154 procesos de nombramiento incluidos en la Tabla 1, existen otros 31 casos correspondientes a organismos que dejaron de funcionar, pero carecen de un sucesor claramente establecido. Esto es lo que sucede con 20 procesos de nombramiento en la Comisión Resolutiva, así como otros 11 en la Comisión Nacional del Medio Ambiente. De manera agregada, la base de datos construida para efectos de este trabajo reúne información sobre los 185 nombramientos directivos que se realizaron entre los años 1990 y 2016. Es importante destacar que si bien existe un proceso de selección a nivel de la definición de las agencias regulatorias incluidas en el estudio, respecto de cada una de ellas se recolectó información sobre la totalidad de los nombramientos directivos ${ }^{39}$.

37 Por esta razón, una planta mediana cercana a los 150 funcionarios resulta más ilustrativa que el promedio de 500 funcionarios señalado en la tabla. Por otra parte, también podría objetarse que las prácticas de contratación de personal en Chile exigen considerar los contratos a plazo fijo y los contratos a honorarios. El problema es que la LeY 20.285 de 2008, sobre acceso a la información pública, comenzó a regir bastante después de 1990, el año de inicio de nuestro período de análisis. En cualquier caso, los datos de personal disponibles vía transparencia y la magnitud del presupuesto anual confirman el tamaño relativo de las agencias consignado en la Tabla 1.

38 Cordero y García (2012).

39 El proceso de recolección de datos se dividió en dos etapas sucesivas. La primera de ellas consistió en reconstruir la historia institucional de cada una de las agencias, incluyendo una definición de los periodos institucionalmente relevantes y un listado de todas sus autoridades superiores. Posteriormente, para aquellos periodos ocurridos después de 1990 se registraron distintas variables relativas al proceso de nombramiento. De manera 
En términos generales, existen dos grupos de datos relevantes. Por una parte, están los datos relativos al proceso de nombramiento, incluyendo el nivel de control con que cuenta el Poder Ejecutivo y el tipo de mecanismos de transparencia formalmente incorporados. Por otra, también resulta interesante analizar los datos biográficos de las personas seleccionadas, incluyendo su nivel de calificación profesional y la intensidad de su afiliación política. En esta sección se discute el primero de estos grupos de datos, mientras que la revisión del segundo se realiza en la sección siguiente.

Respecto de la estructura del proceso de nombramiento, resulta llamativo que la generalidad de los estudios comparados le otorgue tan poca importancia. Si tomamos como ejemplo los índices desarrollados por Gilardi ${ }^{40}$ y Ennser-Jedenastik ${ }^{41}$, seguramente los más utilizados en esta materia, en ellos se compilan respuestas estructuradas a una veintena de preguntas relativas al diseño institucional de la agencia. De ellas, solamente una pregunta se refiere al proceso de nombramiento y apunta a calificar como más independiente aquellos procesos donde el Poder Ejecutivo tiene menos influencia ${ }^{42}$. Tomando esta idea fuerza, el enfoque que propone este estudio busca hacer más complejo y extensivo el análisis del proceso de nombramientos en tres aspectos específicos.

En primer lugar, la literatura tiende a enfocarse en la relación entre el Presidente de la República y el Congreso, particularmente en si la ley exige una confirmación del nombramiento por parte del Senado ${ }^{43}$. Ello, sin embargo, deja fuera un conjunto de mecanismos desarrollados en la práctica administrativa nacional. Es lo que sucede con el TDLC, donde en algunos nombramientos interviene la Corte Suprema y en otros el Banco Central. Algo similar sucede con el Panel de Expertos, donde los nombramientos son realizados por el propio TDLC. Finalmente, en Chile se hace cada vez más frecuente la intervención del sistema de Alta Dirección Pública, un organismo especializado en la selección de personal para cargos directivos, diseñado para limitar la influencia del Poder Ejecutivo ${ }^{44}$. Por ello, el análisis desarrollado en este trabajo busca identificar los distintos mecanismos para limitar la discrecionalidad del gobierno, antes que concentrarse en el balance de poder entre los poderes Ejecutivo y Legislativo.

En segundo lugar, resulta conveniente dividir el proceso de nombramiento en etapas, distinguiendo entre la selección de candidatos, la designación de los directivos y su confir-

similar, para cada persona que ocupó una posición directiva después de 1990 se desarrolló una biografía. El detalle con las fichas de investigación para cada institución puede consultarse en: https://www.researchgate.net/ project/Dieseno-institucional-de-la-agencias-regulatorias-independientes-ARI-en-Chile.

40 Gilardi (2002).

41 ENNSER-JEDENASTIK (2015).

42 Ambos índices establecen un conjunto de respuestas tipo para cada pregunta, las cuales tienen asignado un puntaje que va entre el 1 que señaliza mayor independencia, y el 0 que señaliza menor independencia. Tratándose de los nombramientos de los directivos de la agencia, existen cinco posibles respuestas a la pregunta ¿quién designa a las autoridades superiores?: (i) uno o dos ministros, que recibe un puntaje igual a 0; (ii) el Poder Ejecutivo colectivamente, que recibe un puntaje igual a 0,25; (iii) el Poder Legislativo, que recibe un puntaje igual a 0,5 ; (iv) un proceso donde participan ambos poderes, que recibe un puntaje igual a 0,75 , y (v) autogeneración por la propia agencia, que recibe un puntaje igual a 1.

43 V. g. García y Verdugo (2010).

44 GonzÁlez-Bustamante et al. (2016). 
mación posterior. La regla general en nuestra práctica administrativa es que la designación sea realizada por el Poder Ejecutivo ${ }^{45}$. En 93 de los 185 nombramientos analizados, la designación se realizó sin ningún tipo de contrapeso. Ello es equivalente a considerar que, en cerca de la mitad de los nombramientos, las tres etapas referidas anteriormente fueron controladas íntegramente por el Poder Ejecutivo. Enfocándonos ahora en la otra mitad de los casos, un $17 \%$ del total corresponde a nombramientos donde el gobierno decide discrecionalmente la selección y designación de candidatos, sometiéndose luego al proceso de confirmación por parte del Senado. Estos 31 nombramientos corresponden a 19 consejeros del Banco Central, 7 del CPLT y 5 contralores generales ${ }^{46}$.

En contraste, un 33\% de los casos corresponde a nombramientos donde el proceso de selección fue realizado por algún organismo que sirve de contrapeso al gobierno. Tratándose del TDLC, existen 3 ministros (1,6\% del total) cuyo su proceso de selección fue realizado por la Corte Suprema mediante la confección de una quina de candidatos, mientras que en el caso de los restantes 8 ministros (4,2\% del total) la selección fue realizada por el Banco Central. Respecto del Panel de Expertos, existen 11 nombramientos (5,9\% del total) cuyo proceso de selección se realizó por el TDLC. Finalmente, en las restantes agencias existen 39 casos ( $21 \%$ del total) donde la selección de candidatos y confección de ternas se realizó a través de ADP. Un aspecto a destacar es que, en nuestra práctica administrativa, los mecanismos de independencia formal son puestos alternativamente en las etapas de selección o de confirmación. Ningún sistema de nombramiento para agencias regulatorias contempla mecanismos de independencia en ambas etapas.

En tercer lugar, es importante analizar separadamente la incorporación de una serie de medidas de transparencia. Así, por ejemplo, la selección de candidatos puede realizarse precedida de un concurso abierto o cerrado. La realización de concursos públicos tuvo lugar en 81 casos (43,7\% del total), generalmente asociados a procesos de selección liderados por el Banco Central y el sistema de ADP. A su vez, también pueden realizarse audiencias públicas con los candidatos. El proceso de confirmación ante el Senado típicamente involucra la comparecencia del candidato en el hemiciclo, donde se realiza una ronda de preguntas antes de proceder a la votación. Por otra parte, los procesos de selección realizados por la Corte Suprema suelen incorporar una instancia donde los candidatos realizan una presentación abierta al público. Lamentablemente, las audiencias, oposiciones y entrevistas públicas no están generalmente incorporadas dentro del procedimiento administrativo de nombramiento, por lo que carecemos de un registro formal para estas actividades. Una revisión de la prensa para cada uno de los nombramientos involucrados muestra que este tipo de medidas de transparencia se habrían aplicado en 38 casos adicionales (20,5\% del

45 La única excepción estaría constituida por una minoría de ministros del TDLC cuya selección y designación se realiza directamente por el Banco Central. Solamente cuatro casos en la base de datos se realizaron conforme a este procedimiento, representando un $2 \%$ del total.

46 Con todo, es importante recordar que los quórums de confirmación en cada caso son bastante diferentes. Para confirmar un nombramiento para el Banco Central basta la mayoría simple, mientras que para el CPLT se exigen dos tercios y para la CGR tres quintos. 
total $)^{47}$. Por lo tanto, existirían 66 procesos de nombramientos $(35,6 \%$ del total) completamente cerrados, esto es, realizados sin ninguna medida de transparencia.

Tratándose de los tres aspectos revisados anteriormente, sin embargo, hay que tener en cuenta la dimensión temporal. El sistema de ADP empezó a funcionar recién en el año 2003 y comenzó a implementarse progresivamente. Aunque respecto del total solamente un quinto de los nombramientos se realizó con la participación del sistema de ADP, en los últimos 5 años esa proporción es cercana a los dos tercios de los procesos de selección que se realizaron. Algo similar ocurre en materia de concursos públicos. Como se aprecia en la Figura 1, existe una clara tendencia al alza en la fracción anual de procesos de selección que estuvieron precedidos de un concurso público. Ciertamente la incorporación progresiva del sistema de ADP explica una parte de este aumento. Ahora bien, la tendencia parece comenzar algunos años antes ${ }^{48}$. Por otra parte, después del año 2003 también se incorporan otros organismos cuya práctica general es hacer concursos públicos, como sucede con el Banco Central y el TDLC. En definitiva, aunque los resultados globales muestran una realidad preocupante, donde la mayoría de los nombramientos son controlados de principio a fin por el gobierno y la aplicación de mecanismos de transparencia resulta escasa, ambas circunstancias han ido mejorando desde 1990.

Existe otro aspecto de esta dimensión temporal que vale la pena tener en cuenta. La sección inferior de la Figura 1 muestra la cantidad de nombramientos realizados anualmente entre 1990 y 2016. Además, para facilitar la visualización del argumento que a continuación se analiza, se muestra también el año de inicio de cada período presidencial. La primera tendencia que conviene destacar dice relación con el ciclo electoral que parecieran seguir los nombramientos en nuestras agencias regulatorias. La menor cantidad de nombramientos anuales típicamente ocurre en los últimos años de un período presidencial, mientras que la mayor cantidad típicamente ocurre durante el año de instalación ${ }^{49}$. De hecho, durante los cinco periodos presidenciales, la cantidad de nombramientos en el año inicial es significativamente mayor a la cantidad de nombramientos en el año final ${ }^{50}$. Lo mismo se observa si comparamos el volumen de nombramientos de los gobiernos entrantes y salientes: el último año del gobierno saliente supone muchos menos nombramientos que el primer año del gobierno entrante. Más aún, las cesaciones en los cargos directivos siguen un

47 El proceso de revisión supuso búsquedas en internet, así como la revisión de archivos de prensa en fechas cercanas a la designación de los candidatos. Una explicación completa de los protocolos para el levantamiento de información puede encontrarse en: https:/www.researchgate.net/project/Dieseno-institucional-de-la-agencias-regulatorias-independientes-ARI-en-Chile.

48 Aunque las variaciones anuales van en diferentes sentidos, durante los 13 años anteriores a 2003 existe un aumento promedio cercano al $10 \%$ anual. Con todo, una revisión casual de los datos muestra que durante el periodo 1990-2002 hay una gran variabilidad, existiendo tanto aumentos como disminuciones en la fracción de concursos realizados. De hecho, este $10 \%$ de aumento promedio responde principalmente a los aumentos de los años 1993, 1996 y 2001, los que típicamente vinieron precedidos por años donde la fracción de concursos fue cero.

49 La excepción a esta tendencia se encuentra en el máximo global de la muestra, que muestra 16 nombramientos en agencias durante el año 2004, cerca de la mitad del período presidencial de Lagos.

50 En promedio, la cantidad de nombramientos en el último año presidencial son un $72 \%$ menos que en el primero. La menor diferencia en este ámbito se observa en el período de Frei, donde alcanza un 57\%, la mayor en el primer período de Bachelet, donde alcanza un $87 \%$. 
patrón similar: de los 27 años en el período en estudio, solamente $6(22 \%)$ corresponden al primer año de instalación de un gobierno. No obstante, en estos primeros años de instalación se produjeron 60 de las 153 cesaciones de cargos (39\%) donde existe una fecha cierta. En términos generales, todos estos antecedentes sugieren tomar con cautela el optimismo del párrafo anterior: la existencia de un ciclo electoral en los nombramientos suele ser indicio de la incapacidad de los mecanismos de independencia formal para conseguir niveles reales de independencia dentro de las agencias regulatorias ${ }^{51}$.

Figura 1: Cantidad de concursos y nombramientos por año (1990-2016) ${ }^{52}$
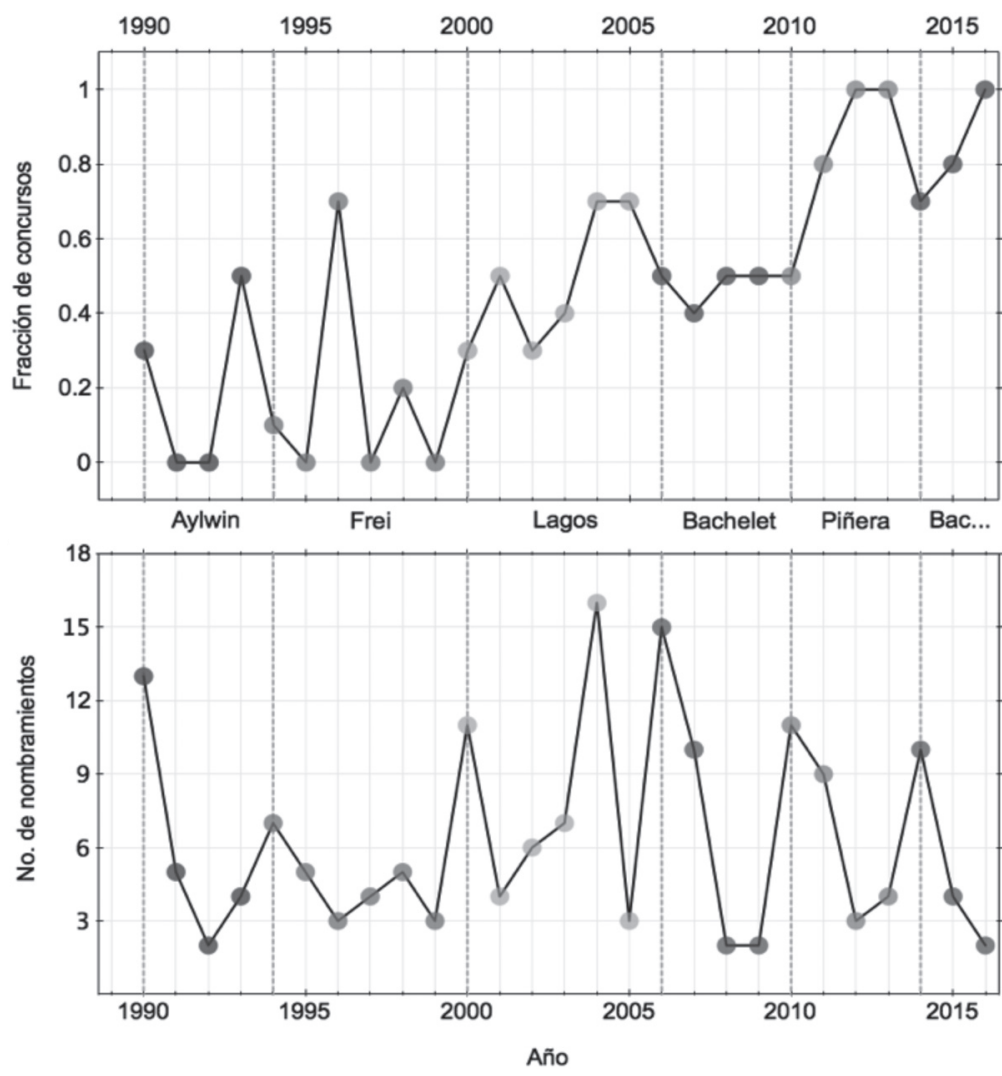

Finalmente, también conviene analizar de manera comparada la cantidad de nombramientos y la fracción de concursos. En los dos gobiernos que se encuentran al comienzo del período estudiado, correspondientes a los presidentes Aylwin y Frei, la tendencia al alza en la fracción de concursos públicos es menos pronunciada. No obstante, también es menos pronunciado el ciclo electoral en la cantidad de nombramientos. En contraste, en

\footnotetext{
51 ENNSER-JEDENASTIK (2015).

52 Los puntos reflejan la fracción de concursos realizados dentro del año correspondiente (arriba), o la suma de nombramientos (abajo). El color del punto refleja los distintos períodos presidenciales en el período estudiado. Para facilitar la visualización se incluye una línea que une cada punto mostrando la tendencia de los datos, así como una línea vertical segmentada mostrando el cambio de período presidencial.
} 
los dos últimos gobiernos del período, correspondientes a los presidentes Piñera y Bachelet, existe una clara tendencia creciente en la fracción de nombramientos, pero también una disminución importante en la cantidad de nombramientos después del primer año de instalación. En otras palabras, el año en que ambos presidentes hicieron una mayor proporción de concursos, fue aquel en que hicieron menos nombramientos, y viceversa. Estos otros antecedentes también sugieren contener el optimismo inicial.

\section{CALIDAD PROFESIONAL Y AFILIACIÓN POLÍTICA}

La segunda sección de este trabajo mostró las características del diseño institucional de nuestras agencias regulatorias. La tercera sección hizo lo propio con los procesos de nombramiento de los directivos de estas agencias. En esta sección corresponde analizar las biografías de los directivos que fueron efectivamente seleccionados. Para estos efectos, conviene recordar que, en materia de nombramientos directivos, los mecanismos de independencia formal persiguen dos objetivos diferentes: por una parte, buscan limitar la capacidad del Poder Ejecutivo para premiar y castigar la lealtad política; por otra, buscan profesionalizar las agencias y hacer más técnicos sus procesos de toma de decisiones. Desde esta perspectiva, resulta razonable concentrarse en los aspectos de las biografías que reflejen la afiliación política y calidad profesional de cada directivo ${ }^{53}$.

Para facilitar el análisis de ambos aspectos, se construyeron dos índices diferentes pero con una metodología similar. Tratándose de la afiliación política, el índice es el resultado de un conjunto de preguntas estructuradas acerca de la posible militancia en un partido político, la participación en una elección popular, en cargos de confianza exclusiva, en centros de estudios, en organizaciones no gubernamentales, y otras semejantes ${ }^{54}$. Las respuestas a todas estas preguntas están diseñadas para oscilar entre cero y uno. Por ello, un simple promedio permite reflejar la intensidad de la afiliación política en términos absolutos, esto es, sin identificar a las personas dentro un eje valorativo como izquierda-derecha o liberal-conservador ${ }^{55}$. Con relación a la calidad profesional, el índice se construye de manera similar a las metodologías con que se asignan becas o fondos de investigación, donde

53 V.g., Joignant et al. (2012).

54 La calidad de militante es evaluada en términos binarios, al igual que la calidad de simpatizante. Esto último se construye mediante búsquedas en los medios de prensa, considerándose a una persona como simpatizante de un partido cuando al menos tres noticias diferentes y sin relación entre ellas realizan dicha asociación. En contraste, la cantidad de participaciones en elecciones o en cargos de confianza exclusiva, así como la pertenencia a centros de estudios, corporaciones y fundaciones vinculadas a un partido político, son evaluadas como una fracción respecto del número máximo observado en la muestra. Para una descripción detallada de esta metodología ver LEWIS (2007).

55 Así, por ejemplo, dentro del TDLC podemos encontrar una importante variación en términos del índice de afiliación política. El valor más alto de la muestra corresponde a Eduardo Jara Miranda, cuyo índice de 0,78 refleja el que fuera militante del Partido Radical y haya ocupado distintos cargos de exclusiva confianza, inclusive como Alcalde de la comuna de Las Condes en 1991. En contraste, sobre muchos ministros, como Eduardo Saavedra o Radoslav Depolo, su estudio biográfico no arrojó ningún antecedente sobre participación política y su índice es igual a cero. 
se compila información binaria respecto de la tenencia de un título profesional, con el ranking general de la carrera respectiva ${ }^{56}$.

Si revisamos los 185 directivos nombrados en nuestras agencias regulatorias entre 1990 y 2016, cerca de una centena son economistas o ingenieros, mientras que otros 75 son abogados. Estas tres profesiones representan un 95\% del total, mientras que el 5\% restante corresponde a periodistas, sociólogos, profesores y otras carreras. Respecto de la institución educacional de procedencia, la Universidad de Chile concentra bastante más de la mitad de los datos y la Pontificia Universidad Católica cerca de otro cuarto, en conjunto representan un $85 \%$ de los nombramientos y ningún otro plantel académico supera un 3\% adicional. Finalmente, un $44 \%$ de los directivos contaba con estudios de magíster al momento de su nombramiento, mientras que otro 23\% tenía además estudios de doctorado.

Como sucede con la generalidad de los índices, sin embargo, la unidad de medida resulta poco intuitiva y muchas situaciones particulares quedan reflejadas de manera equívoca. Por esta razón, el análisis que sigue se centra en el comportamiento de los datos a nivel agregado, esto es, sin realizar un análisis individual de los resultados para cada persona.

Figura 2: Calidad profesional y afiliación política para cada tipo de agencia $(1990-2016)^{57}$

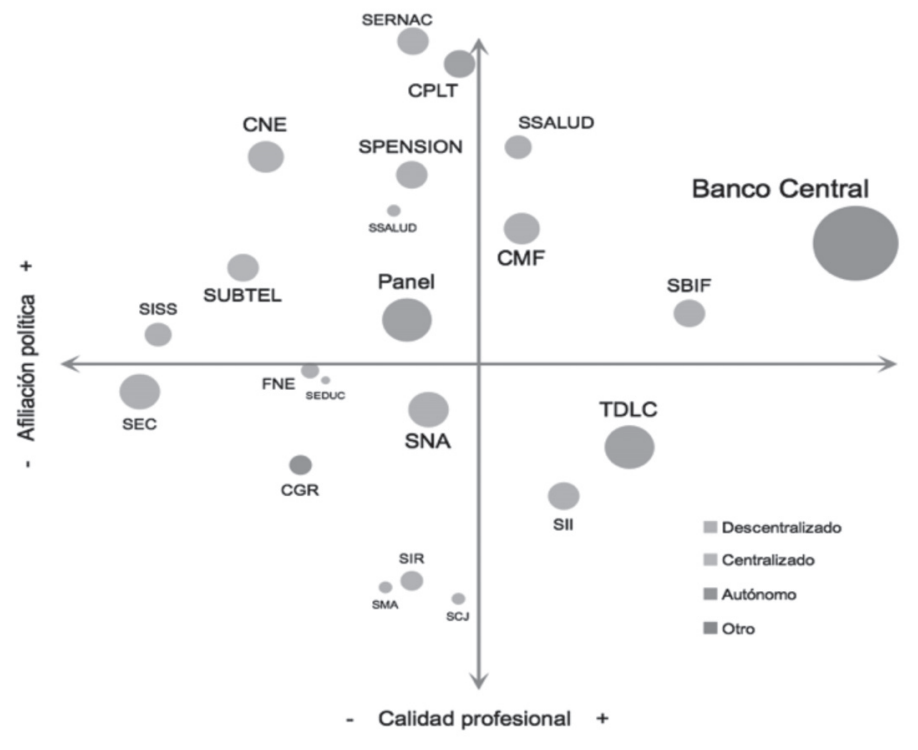

\footnotetext{
56 Ver, Bach y Veit (2017).

57 El eje horizontal muestra el índice de calidad profesional y el eje vertical el índice de intensidad de afiliación política. Ambos índices fueron realizados para este trabajo sobre la base de información pública respecto de las biografías de cada directivo. Los puntos reflejan los valores promedio correspondientes a los nombramientos realizados para cada agencia. El tamaño relativo del punto representa la cantidad de nombramientos en cada institución y su color el tipo de institución involucrada. En color verde se muestran las instituciones descentralizadas, en rosado las centralizadas, en azul las constitucionalmente autónomas y en rojo las que tienen otro diseño institucional. Las flechas grises en el centro de la figura muestran los valores medianos para cada eje. El gráfico omite los valores de cada eje para destacar que lo relevante es la posición relativa de los puntos, sin que exista un significado particular para los órdenes de magnitud de cada índice.
} 
Revisemos en primer lugar los datos agregados a nivel de agencias. Según se muestra en la Figura 2, la interacción de ambos índices muestra varias tendencias interesantes. La mayor parte de las agencias se encuentran en la sección superior-izquierda, con índices de afiliación política relativamente altos y de calidad profesional relativamente bajos. En contraste, la sección inferior-derecha, donde los índices de afiliación política son relativamente bajos y los de calidad profesional relativamente altos, se muestra bastante despoblada. En términos generales, nuestro sistema de nombramientos parece encontrarse en una mala posición respecto de los objetivos perseguidos por los mecanismos de independencia formal.

Pero miremos con mayor detención las agencias situadas en los extremos de la Figura 2. En el tope del eje vertical aparecen el SERNAC y el CPLT, las dos instituciones con mayores índices promedio de afiliación política. Ello obedece a que en ambas instituciones sus directivos típicamente habían ocupado varias posiciones de confianza exclusiva en el gobierno antes de asumir, como sucede con Alejandro Ferreiro y Jorge Drago en el CPLT, o bien lo hicieron después como Luis Sánchez y Alberto Undurraga en el SERNAC. En contraste, en el fondo del eje vertical se encuentran la SIR, la SMA y la SCJ. En estas tres instituciones se realizaron 11 procesos de nombramientos, pero en 8 de ellos no se pudo encontrar ningún antecedente que revelara la afiliación política de los directivos ${ }^{58}$. Finalmente, resulta llamativo que las cinco instituciones situadas en ambos extremos del eje vertical tengan un índice promedio de calidad profesional similar, con valores ligeramente inferiores a la mediana.

Moviéndonos ahora hacia el eje horizontal, el extremo derecho parece confirmar la reputación profesional del Consejo del Banco Central. Con excepción de algunos nombramientos al inicio del período, todos los consejeros de esta institución tienen una biografía profesional excepcional, con estudios de magíster y doctorado en algunas de las mejores universidades del mundo. No obstante, la enorme distancia en el eje horizontal entre el Banco Central y la CGR, otra institución con un mecanismo de nombramiento similar, sugiere hacer una prevención. De las tres profesiones más frecuentes, ingeniería y economía tienen una tradición de internacionalización que lleva varias décadas. En contraste, la realización de posgrados en el extranjero es un fenómeno relativamente reciente para los abogados, por lo que cualquier índice basado en los rankings globales de la universidad de procedencia tiende a generar un sesgo en su contra. Algo ligeramente diferente ocurre en el extremo izquierdo del eje horizontal, donde la posición de la SEC se explica porque el ranking de la carrera de pregrado de algunos de sus directivos es bastante bajo. En definitiva, al tratarse de un índice que refleja posiciones relativas, la calidad profesional pasa a estar dominada por el estándar que fijan el Banco Central o los últimos nombramientos del TDLC: profesionales vinculados a las políticas públicas y con una trayectoria académica

\footnotetext{
58 Además, los tres casos con índices de afiliación política positiva tienen valores relativamente bajos. En los casos de Francisco Leiva de la SCJ y Juan Monckeberg de la SMA, habían trabajado previamente en el Poder Ejecutivo. Por su parte, Rodrigo Albornoz Pollman de la SIR tiene el valor más alto en este subconjunto de datos debido a su militancia en la Democracia Cristiana, con quienes participó en unas elecciones municipales.
} 
destacada, egresados de la Universidad de Chile o la Pontificia Universidad Católica, y doctores en su especialidad por alguna prestigiosa universidad extranjera.

Desde esta perspectiva, sin embargo, agrupar los datos a nivel institucional refleja pocas tendencias. Las dos agencias constitucionalmente autónomas muestran índices muy diferentes, al igual que el CPLT, el Panel de Expertos y el TDLC. Con relación a los servicios descentralizados, las agencias están dispersas en las distintas regiones del plano cartesiano, manteniéndose generalmente cerca de alguno de los ejes que refleja los valores medianos. Quizás la única particularidad sea que las instituciones asociadas al ámbito financiero, en nuestro caso la CMF, la SBIF y el Banco Central, muestran valores relativamente altos en ambos índices. Ello es consistente con la literatura comparada ${ }^{59}$, que generalmente observa un mejor desempeño de los reguladores financieros en las mediciones de independencia formal.

Al contrario, agrupar los datos según el tipo de mecanismo de nombramiento muestra varias tendencias interesantes. Según se muestra en la Figura 3, la primera es que el Poder Ejecutivo domina la mayoría de los procesos de nombramiento, alcanzando niveles de afiliación política y calidad profesional bastante cercanos a la mediana. En comparación, recurrir al sistema de ADP pareciera conseguir uno de los objetivos de la independencia formal al disminuir significativamente la intensidad promedio de la afiliación política. Con todo, el sistema de ADP pareciera ser ineficaz a la hora de aumentar los niveles de calidad profesional. Los nombramientos realizados por esa vía incluso muestran una pequeña disminución en el valor promedio del índice. Ello contrasta con los nombramientos confirmados por el Senado, donde disminuye el valor promedio de índice de afiliación política y aumenta significativamente el de calidad profesional ${ }^{60}$. Los nombramientos donde participan la Corte Suprema, el TDLC o el Banco Central se encuentran a medio camino, con el segundo menor índice promedio en afiliación política y el segundo mayor en calidad profesional.

\footnotetext{
59 V. g. Gilardi (2002).
}

60 Ahora bien, es importante tener en cuenta que ello es consecuencia de lo que suele denominarse como efecto pooling, consistente en promediar dos subconjuntos de datos con resultados contrapuestos. En nuestro caso, los nombramientos de la CGR se caracterizan por tener índices promedio relativamente bajos, tanto en lo político como en lo profesional. Al revés, los nombramientos del Banco Central tienen valores promedio altos en ambos índices. De este modo, los directivos de la CGR empujan al mecanismo de confirmación por el senado hacia la neutralidad política, mientras que los del Banco Central lo empujan hacia una mayor calidad profesional. 
Figura 3: Calidad profesional y afiliación política para cada mecanismo de nombramiento $(1990-2016)^{61}$

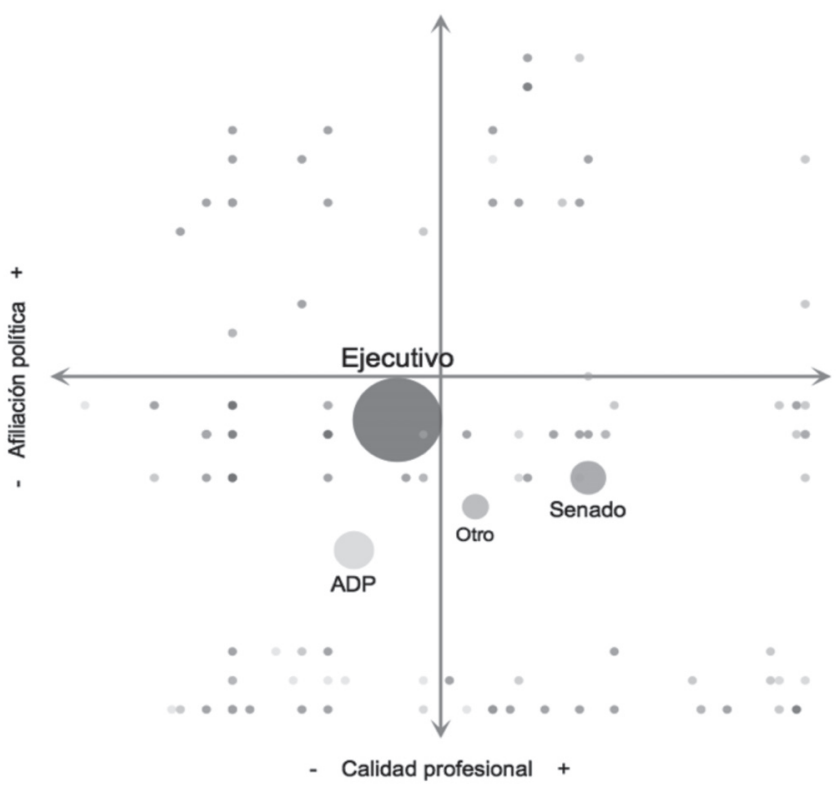

Una explicación completa de estas tendencias requeriría un trabajo completamente dedicado a ello, pero al menos es posible incorporar un grado adicional de complejidad a nuestros estudios biográficos. En particular, es interesante aproximarse a un lugar preferente desde donde cada mecanismo recluta a sus candidatos y el tipo de carrera profesional que siguieron después de dejar la agencia. Tratándose del sistema ADP, un 41\% de los directivos nombrados venía del sector público, típicamente desde posiciones que no eran directivas, y un $57 \%$ se mantiene en dicho sector después. En contraste, en los nombramientos dominados por el Poder Ejecutivo un 36\% venía desde el sector público, típicamente desde

${ }^{61}$ El eje horizontal muestra el índice de calidad profesional y el eje vertical el índice de intensidad de afiliación política. Ambos índices fueron realizados para este trabajo sobre la base de información pública respecto de las biografías de cada directivo. Los puntos pequeños reflejan los valores correspondientes a aquellos nombramientos que dentro de ambos índices tenían valores típicos. El color de cada punto representa los distintos tipos de mecanismos de nombramiento. Los puntos morados muestran procedimientos conducidos exclusivamente por el gobierno, los verdes aquellos donde intervino el sistema de ADP, los naranjos donde lo hizo el Senado y los celestes donde lo hicieron otros organismos. Los cuatro puntos de mayor tamaño muestran el promedio condicional para cada mecanismo de nombramiento y su tamaño relativo la cantidad de nombramientos por tipo de mecanismo. Las flechas grises en el centro de la figura muestran los valores medianos para cada eje. El gráfico omite los valores de cada eje para destacar que lo relevante es la posición relativa de los puntos, sin que exista un significado particular para los órdenes de magnitud de cada índice. 
posiciones directivas previas, y solamente un $49 \%$ se mantuvo en él ${ }^{62}$. Desde esta perspectiva, una posible explicación para las diferencias entre los nombramientos por el sistema ADP y los dominados por el gobierno se encontraría en la tendencia del primero a privilegiar una especie de carrera funcionaria. Lo interesante es que esta carrera tiene ventajas y desventajas, en particular, la mayor neutralidad política vendría a cambio de una menor calidad profesional ${ }^{63}$.

En relación con los resultados de los nombramientos confirmados por el Senado, así como aquellos donde el proceso de selección fue realizado la Corte Suprema, el TDLC o el Banco Central, la clave pareciera estar en su proporción para reclutar personal proveniente de ambientes académicos. En ambos tipos de sistemas de nombramiento, más de un 35\% corresponde a personas cuya dedicación principal era desempeñarse como profesores universitarios. Esta proporción es significativamente menor en los otros dos tipos de nombramientos: un $15 \%$ de los nombramientos dominados por el Poder Ejecutivo correspondían a profesores universitarios y solamente un $10 \%$ en el caso del sistema de ADP. Teniendo en cuenta que nuestro índice de calidad profesional depende en gran medida de los rankings de las carreras de pregrado y postgrado, resulta lógico que obtengan mejores resultados aquellos sistemas de nombramiento donde existe una mayor proporción de profesores universitarios.

\section{CONCLUSIONES}

En términos generales, el equivalente chileno para las agencias regulatorias independientes sigue el modelo de las superintendencias, esto es, servicios públicos legalmente descentralizados y bajo la dirección de una autoridad unipersonal. Desde 1990 a 2003 dicha autoridad era nombrada y removida discrecionalmente por el Poder Ejecutivo, pero desde este último año el sistema ADP ha ido progresivamente restringiendo la discrecionalidad de los nombramientos. Los efectos de este movimiento han sido mixtos. Dentro de lo que la literatura denomina como eje estabilidad-legitimidad, la incorporación del sistema ADP pareciera disminuir los niveles de afiliación política de los directivos. No obstante, sigue existiendo un marcado patrón electoral en los nombramientos y la duración promedio de los directivos varía muy poco.

Bajo este contexto, exhiben mucho mejores resultados los procesos de selección llevados a cabo por la Corte Suprema, el TDLC o el Banco Central, así como también aquellos que están sujetos a confirmación por parte del Senado. En todos estos casos existe

62 De hecho, el estudio biográfico muestra que un 37\% de los directivos nombrados por el Ejecutivo emigra a la industria regulada una vez que cesa en su cargo, lo cual es consistente con estudios previos acerca del fenómeno de puerta giratoria en Chile (MAillet et al., 2016) Más allá del valor relativo que tenga ese número, es importante que estudios sobre el mismo grupo de datos muestren resultados similares.

63 Durante el proceso de discusión de este trabajo, una observación recurrente fue que los concursos públicos podían generar un problema, ya que los buenos candidatos se encuentran generalmente satisfechos con su situación laboral previa y solamente estarían dispuestos a participar en un proceso de selección cuando existen garantías de éxito. La base de datos únicamente recoge datos de las personas efectivamente nombradas, por lo que resulta imposible evaluar la calidad profesional del conjunto de candidatos. No obstante, el argumento parece plausible a la luz de la evidencia de otros trabajos, v. g., GonzÁlez-Bustamante et al. (2016). 
un período de duración nominal fijo, lo que redunda en una duración efectiva cercana a un $50 \%$ mayor que la de los servicios que siguen el modelo de las superintendencias. Además, las agencias donde se siguen estos otros sistemas de nombramiento tienen órganos de dirección colegiados y su renovación se realiza por parcialidades, contribuyendo ambas cosas a desacoplar las instituciones del ciclo electoral. No obstante, la generalidad de estos nombramientos muestran mayores niveles de afiliación política que los desarrollados por el sistema de ADP, y en el caso del CPLT, mucho mayores.

En relación con el eje tecnicismo-armonía, la calidad profesional de los nombramientos realizados en agencias que siguen el modelo de las superintendencias es inferior a la mediana, tanto si el proceso es controlado por el gobierno como si interviene el sistema de ADP. Ello contrasta con lo que sucede en los otros sistemas de nombramiento, donde la calidad profesional de sus directivos es superior a la mediana, y en el caso del Banco Central, muy superior. Con todo, nuestro índice de calidad profesional se basa en los rankings de las universidades donde se formaron profesionalmente los directivos, por lo que tiene un sesgo favorable a los profesores universitarios, así como a profesiones como la economía o la ingeniería.

En definitiva, parece razonable seguir avanzando hacia cuerpos colegiados y mayores niveles de transparencia. También parece necesario estudiar con mayor detención las fortalezas y debilidades de los distintos sistemas de selección. El sistema de ADP parece estar bien equipado para perseguir la neutralidad política, mientras que el Banco Central y el TDLC se muestran capaces de conseguir mejores profesionales. Quizás un nuevo sistema podría combinar lo mejor de ambos mundos. Finalmente, hace falta mayor investigación para entender las diferencias que genera la confirmación por parte del Senado en los nombramientos del CPLT, la CGR y el Banco Central. Más allá de las deficiencias en los índices desarrollados en este trabajo, pareciera que los quórums de aprobación y el sistema de renovación por parcialidades hace una diferencia. En concreto, el sistema del Banco Central que tiene un quórum de mayoría simple y renovación singular muestra mejores resultados que los otros dos. Una comprobación definitiva de esta intuición, sin embargo, requiere un conjunto adicional de información que espero abordar en futuras investigaciones.

\section{BIBLIOGRAFÍA CITADA}

BACH, Tobias y VeIT, Sylvia (2017): "The determinants of promotion to high public office in Germany: Partisan loyalty, political craft, or managerial competencies?”, Journal of Public Administration Research and Theory, vol. 28, No 2: pp. 255-269.

BAWN, Kathleen (1995): "Political control versus expertise: Congressional choices about administrative procedures", American Political Science Review, vol. LXXXIX, No 1: pp. 62-73.

BuzBEE, William (2003): "Recognizing the regulatory commons: A theory of regulatory gaps”, Iowa Law Review, vol. LXXXIX: pp. 1-35.

Carmona, Carlos (2005): Una aproximación general sobre las superintendencias desde la perspectiva del Derecho (Santiago, inédito, en consulta con el autor). 
Cavallo, Ascanio (1998): La historia oculta de la Transición: Chile 1990-1998 (Santiago, Grijalbo).

Cordero, Luis (2015): Lecciones de Derecho Administrativo (Santiago, Thomson Reuters).

Drake, Paul (1989): The money doctor in the Andes: the Kemmerer missions, 1923-1933 (Duke, Duke University Press).

EnNSER-JeDENASTIK, Laurenz (2015): “The politicization of regulatory agencies: Between partisan influence and formal independence", Journal of Public Administration Research and Theory, vol. XXVI, $\mathrm{N}^{\circ}$ 3: pp. 507-518.

Epstein, David y O'Halloran, Sharyn (1999): Delegating powers: A transaction cost politics approach to policy making under separate powers (New York, Cambridge University Press).

Freeman, Jody y Rossi, Jim (2012): "Agency coordination in shared regulatory space", Harvard Law Review, vol. CXXV, N 5: pp. 1131-1211.

Gailmard, Sean (2002): "Expertise, subversion, and bureaucratic discretion", Journal of Law, Economics and Organization, vol. XVIII, N²: pp. 536-555.

García, José Francisco (2009): “¿Inflación de superintendencias? Un diagnóstico crítico desde el Derecho Regulatorio", Actualidad Jurídica Universidad del Desarrollo, vol. IX: pp. 319-372.

García, José Francisco y Cordero, Luis (2012): "Elementos para la discusión sobre agencias independientes en Chile. El caso de las superintendencias", Anuario de Derecho Público (UDP), vol. II: pp. 415-435.

García, José Francisco y Verdugo, Sergio (2010): “De las Superintendencias a las Agencias Regulatorias Independientes en Chile: Aspectos Constitucionales y de Diseño Regulatorio", Actualidad Jurídica Universidad del Desarrollo, vol. XXII: pp. 263-305.

Gilard, Fabrizio (2002): "Policy credibility and delegation to independent regulatory agencies: a comparative empirical analysis", Journal of European Public Policy, vol. IX, $\mathrm{N}^{\circ}$ 9: pp. 873-893.

González-Bustamante, Bastián, Olivares, Alejandro, Abarca, Pedro y Molina, Esteban (2016): "Servicio civil en Chile, análisis de los directivos de primer nivel jerárquico (2003-13)”, Revista de Administração Pública, vol. L, N 50: pp. 59-79.

Huneeus, Carlos (2000): "Technocrats and politicians in an authoritarian regime: The 'ODEPLAN boys' and the 'gremialists' in Pinochet's Chile", Journal of Latin American Studies, vol. XXXII, N²: pp. 450-461.

Joignant, Alfredo (2011): "The Politics of Technopols: Resources, Political Competence and Collective Leadership in Chile, 1990-2010", Journal of Latin American Studies, vol. XLIII, No 3: pp. 517-546.

Joignant, Alfredo, Perelló, Lucas, y Torres, Javier (2012): Las fuentes del poder político. Fundamentos para una teoría del capital político a partir de la evidencia chilena. Ponencia preparada para el XXII Congreso Mundial de Ciencia Política (Madrid).

Krause, George y MeIer, Kenneth (edit.) (2003): Politics, policy, and organizations: Frontiers in the scientific study of bureaucracy (Michigan, University of Michigan Press).

Levy, Brian y SpIller, Pablo (1996): Regulations, Institutions and Commitment (New York, Cambridge University Press). 
LeWIS, David (2004): Presidents and the politics of agency design: Political insulation in the United States government bureaucracy, 1946-1997 (Standford California, Stanford University Press).

LeWIS, David (2007): “Testing Pendleton's premise: Do political appointees make worse bureaucrats?”, Journal of Politics, vol. XDIX: pp. 1073-1088.

Maillet, Antoine, González-Bustamante, Bastián y Olivares, Alejandro (2016): ¿Puerta giratoria? Análisis de la circulación público-privada en Chile (2000-2014), Serie Documentos de Trabajo PNUD - Desigualdad, N²016/07 (Diciembre 2016).

Miller, Geoffrey (1986): “Independent agencies”, The Supreme Court Review, vol. LXXXVI: pp. 86:41-97.

Moran, Michael (2003): The British regulatory state: high modernism and hyper-innovation (Oxford, Oxford University Press on Demand).

Morandé, Felipe y Díaz, Juan (2010): Chile en el Club de los Paises Desarrollados, (Santiago, Ediciones Universidad Católica).

Nehme, Nicole (2011): "Aplicación de las normas de defensa de la competencia a los organismos de la Administración del Estado", en Luders, R. (edit.), La libre competencia en el Chile del Bicentenario (Santiago, Thomson Reuters): pp. 317-75.

Newberry, David M. (2002): Privatization, restructuring, and regulation of network utilities, vol II (Boston, MIT Press).

O'Connell, Anne Joseph (2008): "Vacant offices: Delays in staffing top agency positions", Southern California Law Review, vol. LXXXII: pp. 82: 913-956.

Rajevic, Enrique (2010): "El Consejo para la Transparencia como 'Administración independiente”, en Varios Autores (edit.), Transparencia en la Administración Pública (Santiago, Abeledo Perrot): pp. 231-247.

Roderick, Kiewiet y McCubbins, Mathew (1991): The logic of delegation (Chicago, University of Chicago Press).

Rose-AcKerman, Susan (1986): "Reforming public bureaucracy through economic incentives?”, Journal of Law, Economics and Organization, vol. II, N 1: pp. 131-161.

STEPHENSON, Matthew (2007): "Bureaucratic decision costs and endogenous agency expertise”, Journal of Law, Economics and Organization, vol. XXIII, N²: pp. 469-498.

Tirole, Jean (1994): "The internal organization of government", Oxford Economic Papers, vol. XLVI, $N^{\circ} 1$ : pp. 1-29.

Vergara, Alejandro (2005): "El contencioso administrativo en materia eléctrica: Naturaleza jurisdiccional de las funciones del Panel de Expertos", Revista de Derecho de la Universidad Finis Terrae, Vol. IX: pp. 207-229.

Vergara, Alejandro (2018): "Autoridades administrativas independientes (agencias): Mito y realidad de un modelo conveniente para Chile", Revista de Derecho Administrativo Económico, Vol. XXV: pp. 45-58.

Weber, Max (1964): Economía y sociedad, José Medina y otros [trad.] (México, Fondo de Cultura Económica).

WiLSON, James (1989): Bureaucracy: What government agencies do and why they do it (New York, Basic Books). 
Wood, Dan y Bothe, John (2004): "Political transaction costs and the politics of administrative design", Journal of Politics, vol. LXVI, N 1: pp. 176-202.

ZúNIIGA, Francisco (2007): "Autonomías constitucionales e instituciones contramayoritarias”, Ius et Praxis, Vol. XIII, N²: pp. 223-244.

\section{NORMAS CITADAS}

LEY 20.285 (20/08/2008), sobre acceso a la información pública. 